\title{
Fluxos migratórios no estado de Mato Grosso do Sul (1970-2010)
}

Migratory flows in the state of Mato Grosso do Sul (1970-2010)

\section{Les flux migratoires dans l'état du Mato Grosso do Sul (1970-2010)}

Flujos migratorios en el estado de Mato Grosso do Sul (1970-2010)

\author{
Alexandre de Souza Corrêa ${ }^{1}$ \\ Marcelino Armindo Monteiro ${ }^{2}$ \\ Ricardo Rippel ${ }^{2}$ \\ Eliane Aparecida Gracioli Rodrigues ${ }^{2}$
}

Recebido em 14/05/2017; revisado e aprovado em 25/07/2017; aceito em 16/08/2017

DOI: http://dx.doi.org/10.20435/inter.v19i2.1599

\begin{abstract}
Resumo: O objetivo deste artigo foi analisar a evolução da concentração populacional urbana e rural do estado de Mato Grosso do Sul, entre os anos de 1970 e 2010. Foram utilizados indicadores de localização, por meio do Quociente Locacional e o Coeficiente de Localização; e indicadores de redistribuição populacional, medido pelo Coeficiente de Redistribuição. Por meio de uma análise descritiva de alguns parâmetros observados sobre o fluxo migratório, constatou-se que os mesmos municípios que concentravam população nas décadas de 1970 e 1980, ainda a concentram no período recente.
\end{abstract}

Palavras-chave: planejamento; movimentos demográficos; migração.

Abstract: The objective of this article was to analyze the evolution of urban and rural population concentration in the state of Mato Grosso do Sul between 1970 and 2010. Localization indicators were used, using the Locational Quotient and Location Coefficient; And indicators of population redistribution, as measured by the Redistribution Coefficient. By means of a descriptive analysis of some observed parameters on the migratory flow, it was verified that the same municipalities that concentrated population in the decades of 1970 and 1980, still concentrate in the recent period.

Keywords: planning; demographic movements; migration.

Résumé: L'objectif de cette étude était d'analyser l'évolution de la densité de la population urbaine et rurale dans l'État du Mato Grosso do Sul, entre les années 1970 et 2010. Les indicateurs d'emplacement ont été utilisés par l'emplacement Quotient et le coefficient de localisation; et la redistribution de la population de I'indicateur mesuré par le coefficient de redistribution. Grâce à une analyse descriptive de certains paramètres observés sur la migration, il a été constaté que les mêmes municipalités qui concentrent la population dans les années 1970 et 1980, encore concentrés dans la période récente.

Mots-clés: planification; mouvements demographiques; migration.

Resumen: El objetivo de este estudio fue analizar la evolución de la densidad de población urbana y rural en el estado de Mato Grosso do Sul, entre los años 1970 y 2010. Los indicadores de lugar fueron utilizados por la ubicación Cociente y el coeficiente de localización; y redistribución de la población indicador medido por el coeficiente de redistribución. A través de un análisis descriptivo de algunos parámetros observados en materia de migración, se encontró que los mismos municipios que concentran población en los años 1970 y 1980, siguen concentradas en los últimos tiempos.

Palabras clave: planificación; movimientos demográficos; la migración.

\section{INTRODUÇÃO}

Para compreender os movimentos econômicos e demográficos do estado de Mato Grosso do Sul, é necessário estudar a inserção da Região Centro-Oeste na economia nacional, pois é a partir de políticas de planejamento econômico iniciadas na década de 1930 e intensificadas no decorrer das décadas de 1960 e 1970, que tanto o Centro-Oeste como suas unidades federativas

\footnotetext{
${ }^{1}$ Universidade Federal da Grande Dourados (UFGD), Dourados, Mato Grosso do Sul, Brasil.

2 Universidade Estadual do Oeste do Paraná (UNIOESTE), Campus de Toledo, Paraná, Brasil.
} 
integraram-se com a economia brasileira, por meio de incentivos de ocupação do território da região.

Entre as décadas de 1970 e 1980, a expansão da fronteira agrícola que já iniciara nos estados da Região Sul na década de 1960, principalmente no Paraná, se estendeu fortemente para o estado sul-mato-grossense. Essa expansão ocasionou em uma atração populacional de trabalhadores rurais advindos, principalmente, dos estados da Região Sul e Sudeste, gerando a apropriação extensiva de terras (CUNHA, 1997).

Para Furtado (1963), a evolução da economia mundial moderna advinda da Revolução Industrial evidenciou novos aspectos do subdesenvolvimento, em que resultaram crescentes desequilíbrios sociais, políticos e econômicos nos países da América Latina. Apesar da condição histórica de industrialização e modernização no Brasil, não houve planejamento para mudanças estruturais que superassem a dualidade entre o atrasado e o moderno, ocasionando conflitos sociais causados pela concentração da renda e da terra, acentuando a exclusão social. O Estado acabou por promover processos econômicos de exclusão social, sendo que o progresso para o desenvolvimento estaria na distribuição de renda e terra mais igualitária, como condição necessária para a incorporação de massas urbanas e rurais.

De fato, a expansão da fronteira agrícola é reflexo da modernização no campo. A dualidade entre o atrasado e o moderno, acarretaram em um modelo mais desigual, pois aqueles produtores que não conseguiram se inserir perante a modernização agrícola, acabaram por serem excluídos do processo, o que impactou no deslocamento da mão de obra rural para o urbano. Logo, verificou-se um processo de urbanização acelerado que foi modificando as estruturas produtivas, tanto no urbano quanto no rural (ABRAMOVAY, 1992).

Esses aspectos apontados por Abramovay (1992) coadunam-se com Calixto e Gomes (2014) em seus estudos sobre a inserção de Mato Grosso do Sul ${ }^{3}$ na economia nacional, com o propósito de fornecer bens primários para o capital industrial que se intensificava no Sudeste. Assim, a expansão e a modernização agrícola aceleraram tal processo, fazendo com que o estado tornasse produtor de bens primários estratégicos para o mercado nacional e internacional, nesse caso, na produção de grão e carnes.

Essas perspectivas trouxeram mudanças importantes nos fluxos migratórios do estado, que possibilita, para este estudo, analisar a evolução da concentração populacional urbana e rural do estado de Mato Grosso do Sul, entre os anos de 1970 e 2010. Rippel (2015) em estudo realizado sobre as transformações demográficas no Sudoeste do Paraná já argumentara sobre a questão de que a inserção e unificação dos mercados dos territórios estão ligadas ao comportamento econômico e de sua dinâmica demográfica. Desse modo, este trabalho propõe-se a compreender o perfil de concentração populacional urbana e rural de Mato Grosso do Sul mediante os dados disponíveis nos Censos Demográficos de 1970, 1980, 1991, 2000 e 2010.

Para atender a finalidade deste estudo, faz-se, na segunda seção, uma análise sobre as principais políticas de planejamento para ocupação econômica na Região Centro-Oeste, mais especificamente, no estado de Mato Grosso do Sul. A partir dessa análise, a terceira seção

\footnotetext{
${ }^{3}$ Constituído em 1979, o estado de Mato Grosso do Sul é composto por 79 municípios e tem limites territoriais com cinco estados brasileiros, sendo eles: Paraná (sudoeste), São Paulo (leste), Minas Gerais e Goiás (nordeste) e Mato Grosso (norte); e dois países da América do Sul: Paraguai (sudoeste) e Bolívia (oeste). Os municípios de maiores destaques populacionais e socioeconômicos são a capital Campo Grande, Corumbá, Dourados, Três Lagoas e Ponta Porã.
} 
apresenta os aspectos metodológicos que contribuem para mensurar e identificar a concentração urbana e rural dos municípios do estado, que são o Quociente Locacional, Coeficiente de Localização e o Coeficiente de Redistribuição. Na quarta seção, são apresentados os resultados da pesquisa que evidenciam o perfil da população urbana e rural e, por último, são realizadas as considerações finais do trabalho.

\section{PLANEJAMENTO E OCUPAÇÃO ECONÔMICA NO MATO GROSSO DO SUL}

O crescimento industrial brasileiro durante a primeira metade do século XX ocasionou em mudanças nas estruturas produtivas e de novas divisões regionais do trabalho. A industrialização intensificada na Região Sudeste a partir de 1930 acarretou um movimento de concentração de renda e população, com a formação de um mercado nacional e de novos produtores ligados ao ramo do setor industrial.

Para Fonseca (2015), o incentivo à industrialização caracterizou um projeto desenvolvimentista por vários governos latino-americanos, ainda que não existisse um planejamento que expressasse objetivos, metas e métodos para alcançar tal industrialização. Tal planejamento se tornou importante a partir das contribuições da Cepal na formação de quadros para sua elaboração e execução. A ausência do planejamento não resultou em um Estado ausente, mas sim, presente em menor ou maior grau, como aponta Fonseca (2015, p. 25) "com o afã de imprimir novos rumos à economia, o que fica visível com a criação de instituições, a centralização políticoadministrativa e a ampliação do intervencionismo em muitos deles".

Esses aspectos ascenderam no entendimento de um modelo de desenvolvimento econômico baseado na industrialização para substituição de produtos importados. Assim, as políticas de planejamento varguistas ${ }^{4}$ tornaram-se importantes para o fortalecimento e na transição de um Estado patrimonialista enraizado em oligarquias regionais agrícolas para um Estado burocrático, composto por novos atores políticos e sociais. "O planejamento, até então, estava fortemente referido à ideia de desenvolvimento econômico como industrialização e emancipação econômica nacional, passando agora para uma perspectiva de industrialização associada ao capital internacional" (SOUSA, 2011, p. 190).

Para Kon (1994), o início de um planejamento econômico de feições contínuas e efetivas se deu a partir de 1956, traduzidas no Plano de Metas. Esse plano buscava a eliminação de "pontos de estrangulamentos" que impendiam um processo de desenvolvimento continuado e enfatizava novos setores industriais de produção, ou seja, incentivava o contínuo Processo de Substituição de Importações (PSI) iniciado na década de 1930. Os resultados do plano se deram por meio de investimentos ao setor industrial de ponta (bens de capital), e dos dispêndios do Estado no fornecimento de serviços complementares de infraestrutura, que repercutiria nas próximas décadas.

De acordo com Baer (2003), o Processo de Substituição de Importações em curso nas décadas de 1950 e 1960, caracterizou a migração no sentido rural-urbano e incentivou a ocupação de "espaços vazios", ou seja, espaços não ocupados economicamente na Região Centro-Oeste. Logo, para a consolidação da industrialização brasileira, os estados da região integraram-se, de forma induzida, à economia nacional como fornecedores de matérias primas. Para Bresser-Pereira

\footnotetext{
${ }^{4}$ Governo de Getúlio Vargas (1930-1945).
} 
(2007), essas condições confundem a industrialização como sinônimo de desenvolvimento econômico, em que a sociedade passa a gerar valor adicionado e transferir mão de obra agrícola para o urbano.

Contudo, conforme salienta Singer (1982), a concentração espacial de atividades e de população ao redor de São Paulo culminou na decadência populacional para outras regiões de povoamento antigo, como foi o caso da Região Nordeste. Em resposta às desigualdades regionais evidenciadas, criou-se, em 1959, a Superintendência de Desenvolvimento do Nordeste (SUDENE) e, em 1967, a Superintendência de Desenvolvimento do Centro-Oeste (SUDECO), no entanto o esvaziamento das regiões mais populosas e a descentralização industrial brasileira surtiram efeito somente no início da década de $1970^{5}$.

Diante da conjuntura apresentada, o gradual crescimento econômico e populacional do estado de Mato Grosso do Sul é marcado por políticas de planejamento que visavam à ocupação de territórios nacionais com pouca ou nenhuma dinâmica produtiva e populacional. A criação da Colônia Agrícola de Dourados (CAND) ${ }^{6}$, em 1943, já demonstrara tal preocupação, de que, segundo Abreu (2001), esta servia para a ocupação territorial e no aumento do contingente populacional em áreas de fronteiras internacionais como principais objetivos da política, que consequentemente firmou o estado como extensão de consumidor de bens industrializados e produtor de matérias primas para o Sudeste.

De acordo com Abreu (2001), será a partir da criação da SUDECO, por meio de políticas públicas de Integração Nacional, planejadas pelo regime militar, que o estado se insere economicamente como importante produtor de grãos e carnes para o abastecimento da demanda interna nacional e internacional. Assim, os objetivos da SUDECO eram destinados à integração rodoviária da região com o país, fomentando nas inovações técnicas que transformaram o cerrado do Centro-Oeste capacitado para produção agrícola. Pode-se afirmar que essas intervenções deram a base para a agroindustrialização do estado.

É nesse contexto que essas políticas foram induzindo formas de ocupação do território sul-mato-grossense, com incentivos para a produção agrícola e pecuária por meio de novas técnicas de produção e melhoramento da produtividade. Logo, é a partir das décadas de 1970 e 1980, que o estado passou a ser integrado com atividades agrícolas para exportação, com forma de colaborar com o saldo da balança comercial brasileira. No entanto o desenvolvimento regional integrado para o estado não surtiu efeitos no âmbito do desenvolvimento econômico e social, em que, apesar do aumento da produção de açúcar e álcool, o estado continuou com problemas de concentração de renda (OLIVEIRA, 2003).

Nesse ínterim, os planos de desenvolvimento e colonização para promover a ocupação da Região Centro-Oeste marcaram um processo intenso de crescimento demográfico acima da média nacional, que se estendeu, mesmo com redução da taxa de crescimento populacional, até a década de 1980. Cunha (1997) salienta que esses fatos não estão ligados apenas ao processo de ocupação de fronteiras agrícolas, mas também ao surgimento de aglomerações urbanas, de cidades pequenas e médias em contraste com o perfil agrícola da região.

\footnotetext{
${ }^{5}$ Segundo Fonseca (2015), a instituição de Superintendências corresponde a orientações dos estudos elaborada por teóricos da Cepal.

${ }^{6}$ A criação do estado de Mato Grosso do Sul é datada a partir do ano de 1979. Esta política do Estado de distribuição de terras incentivou a migração de pessoas de vários estados brasileiros, para o sul de Mato Grosso do Sul (OLIVEIRA, 1999).
} 
De acordo com o Plano Estratégico de Desenvolvimento do Centro Oeste (PDCO) (BRASIL, 2007), os planos políticos direcionados ao Centro-Oeste e, respectivamente, para Mato Grosso do Sul, condicionaram por meio da integração físico-territorial e comercial, em conjunto com a ocupação econômica e demográfica da fronteira agrícola entre 1930 e 1980, um novo ciclo de crescimento econômico, com o uso intensivo de tecnologia no campo e novas agroindústrias.

De fato, a partir da década de 1990, com a redução da participação do Estado, este não mais como agente definidor de estratégias, mas sim como regulador do processo de modernização tecnológica vinculada ao capital estrangeiro, surgem discursos voltados para um padrão de desenvolvimento ancorado na globalização e na sustentabilidade. Assim, durante as décadas de 1990 e 2000, são notadas novas cadeias produtivas do agronegócio que diversificaram a estrutura produtiva, sobretudo no processo de urbanização, com crescente aporte do setor de serviços financeiros, educacionais, saúde, saneamento, construção civil etc. (BECKER; EGLER, 1993; BRASIL, 2007).

Bajraj, Villa e Rodrígues (2000), em seus estudos sobre a população e desenvolvimento da América Latina e Caribe, destacaram que o processo de urbanização representava um fator determinante para o desenvolvimento social e econômico de uma região. Porém os autores alertaram para alguns cuidados sobre a expansão da urbanização, que, em muitos casos, marcam problemas de mobilidade em grandes centros urbanos e consequentemente em desigualdades socioeconômicas interurbanas, não se esquecendo dos consequentes problemas rurais, de pequenas propriedades, que se tornam cada vez mais distante de intervenções do Estado.

Diante do exposto, e pelas leituras de Mondardo (2011) e Ferrera de Lima e Alves (2011), pode-se destacar que as transformações econômicas, produtivas e de ocupação populacionais induzidas pelo Estado em Mato Grosso do Sul são de conjunturas macroestruturais, em que os projetos políticos, como a modernização agrícola dos cerrados encabeçada pela SUDECO, foram implementados no âmbito geopolítico, para atender a expansão territorial do modo de produção capitalista. Assim, os movimentos econômicos e populacionais influenciaram, de forma direta, na formação territorial do Centro-Oeste, centralizando a urbanização em territórios estratégicos para expansão do capital agroindustrial e, com a mecanização do campo, impulsionaram o desenvolvimento das atividades de serviços e indústria.

\section{PROCEDIMENTOS METOdOLÓGICOS}

Para compreender os padrões de localização e redistribuição da população urbana e rural do estado de Mato Grosso do Sul, adotou-se, como procedimento metodológico, o emprego de medidas de localização que permitiram diagnosticar o comportamento econômico e demográfico, a fim de verificar possíveis movimentos populacionais que possibilitem entender a dinâmica econômica do estado nas últimas cinco décadas. Conforme Baer (2003), tais dinâmicas são caracterizadas pelo Processo de Substituição de Importações, que culminou na migração rural-urbana para espaços não ocupados economicamente na Região Centro-Oeste.

Como base metodológica, este trabalho recorre ao estudo de Rippel (2015), que analisou as transformações demográficas no Sudoeste do estado do Paraná, destacando o desenvolvimento econômico no âmbito de fluxos migratórios, em que a localização espacial está em constante transformação na região. O autor ainda destaca que trabalhos realizados no Brasil, como de Lodder (1974) e Haddad (1989), analisaram padrões locacionais de desenvolvimento regional por meio 
de instrumentais que auxiliaram no entendimento do estudo voltado às unidades territoriais e a seus desdobramentos quanto ao padrão locacional.

Em Mato Grosso do Sul, poucos são os estudos que abordaram padrões locacionais de população, contudo Cunha (1997) examinou os movimentos migratórios das Unidades Federativas da Região Centro-Oeste na década de 1980, destacando que a fronteira agrícola ainda estava em sua plenitude. Constatou-se, então, um intensificado desenvolvimento econômico e demográfico com grandes contingentes de migração para todos os estados da região.

Assim, para a execução dos instrumentais metodológicos deste trabalho, foi organizado um conjunto de variáveis relacionadas com a população distribuída por situação de domicílios rural ou urbana, disponibilizados pelos Censos Demográficos do Instituto Brasileiro de Geografia e Estatística (IBGE). Com esse conjunto, foi possível construir uma matriz de informações que auxiliaram no cálculo de medidas de localização.

Logo, as seguintes variáveis foram selecionadas:

$P O P_{i j}=$ População no domicílio $i$ do município $j$;

$\sum_{j} P O P_{i j}=$ População no domicílio $i$ do estado;

$\sum_{i} P O P_{i j}=$ População em todos os domicílios do município $j ;$

$\sum_{i} \sum_{j} P O P_{i j}=$ População total do estado.

Pelo Quadro 1, é possível observar a organização das variáveis em uma matriz de informação. De acordo com a população de cada um dos municípios (j) e de cada domicilio (rural ou urbano) de Mato Grosso do Sul, impetra-se na somatória das variáveis apresentadas.

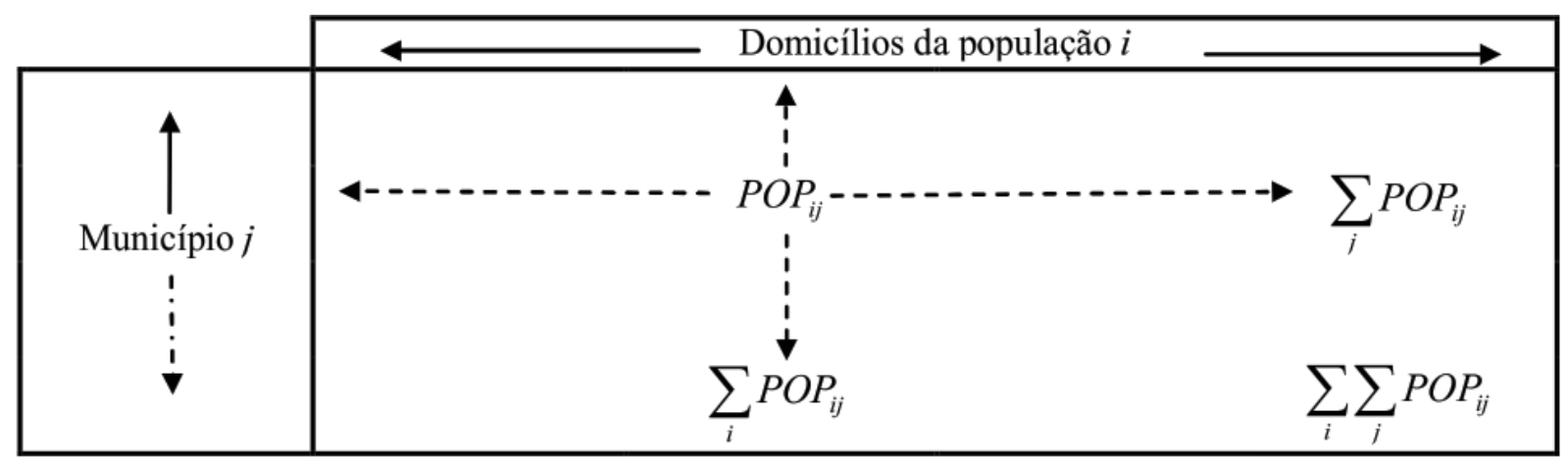

Quadro 1 - Matriz de informações

Fonte: Rippel (2015)

Com base na matriz de informação apresentada no Quadro 1, foi possível calcular as seguintes medidas de localização do espaço territorial do estado:

\section{i) Quociente Locacional (QL)}

O primeiro é o uso do Quociente Locacional (QL), que busca comparar variáveis para determinar padrões espaciais de especialização na economia regional, geralmente baseado em duas estruturas, e neste trabalho foi utilizado a população dos municípios e o domicílio (rural ou urbano). Assim, tem-se a seguinte fórmula: 


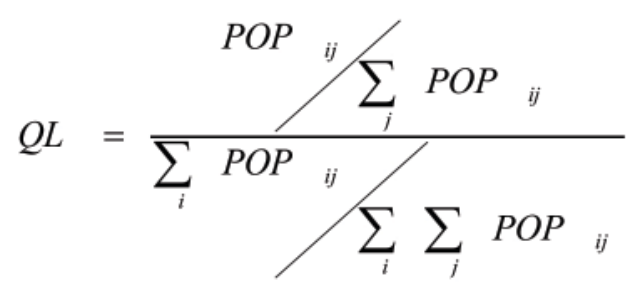

A partir do cálculo do QL, é possível identificar que, se o QL for igual ou maior que um (1), o município se mostrará relevante no âmbito estadual, de acordo com o domicilio estudado, ou seja, apresentará um grau de agrupamento da população domiciliar calculada. Por outro lado, se o QL for menor que um (1), significará que o município tem pouca representatividade de acordo com o domicílio calculado. Assim sendo, essa medida de localização permite compreender quais municípios possuíram ou possuem padrões rurais ou urbanos ao longo do período analisado.

\section{ii) Coeficiente de Localização (CL)}

A segunda medida é o Coeficiente de Localização $(\mathrm{CL})$, este relaciona a proporção populacional de um domicílio com a proporção populacional do estado. Por meio da Equação 2, verifica-se tal relação:

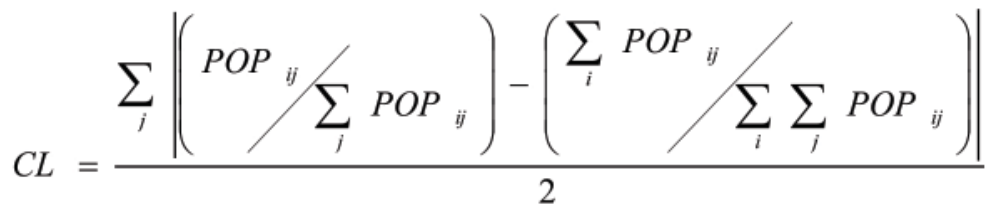

Os valores encontrados variam de 0 a 1, em que valor igual a um (1) sugere que o domicílio i mostra-se concentrado em relação aos demais domicílios. Contudo, se o valor for igual a zero (0), indica que a população do domicílio i estará mais distribuída e de forma análoga entre todos os outros municípios do estado.

\section{iii) Coeficiente de Redistribuição (CRed)}

De acordo com Rippel (2014), esse coeficiente detém características demográficas, econômicas e geográficas, pois relaciona a distribuição percentual da população de um mesmo domicílio em dois períodos, $t_{0}$ (ano inicial) e $t_{1}$ (ano final). Assim, o Coeficiente de Redistribuição, apresentado na Equação 03, permite verificar se estão ocorrendo padrões de concentração ou dispersão espacial para dado domicílio ao longo dos anos verificados.

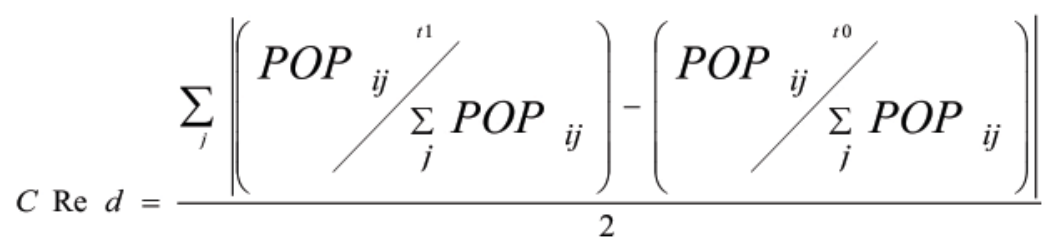

Os resultados desse coeficiente variam entre zero (0) e um (1), sendo que valores próximos a um (1) indicam que os padrões espaciais de localização dos municípios do estado modificaram ao longo do tempo. Entretanto, se o valor for próximo de zero (0), significa que houve poucas mudanças nos padrões espaciais de localização dos municípios. 


\section{PERFIL LOCACIONAL DA POPULAÇÃO SUL-MATO-GROSSENSE}

Na Figura 1, é possível verificar a evolução do Quociente Locacional (QL) da população urbana dos municípios do estado de Mato Grosso do Sul. No âmbito geral, a concentração da população urbana foi diminuindo entre o período de 1970 e 2010, em termos proporcionais, essa concentração reduziu de 37,93\% para 5,64\% respectivamente.

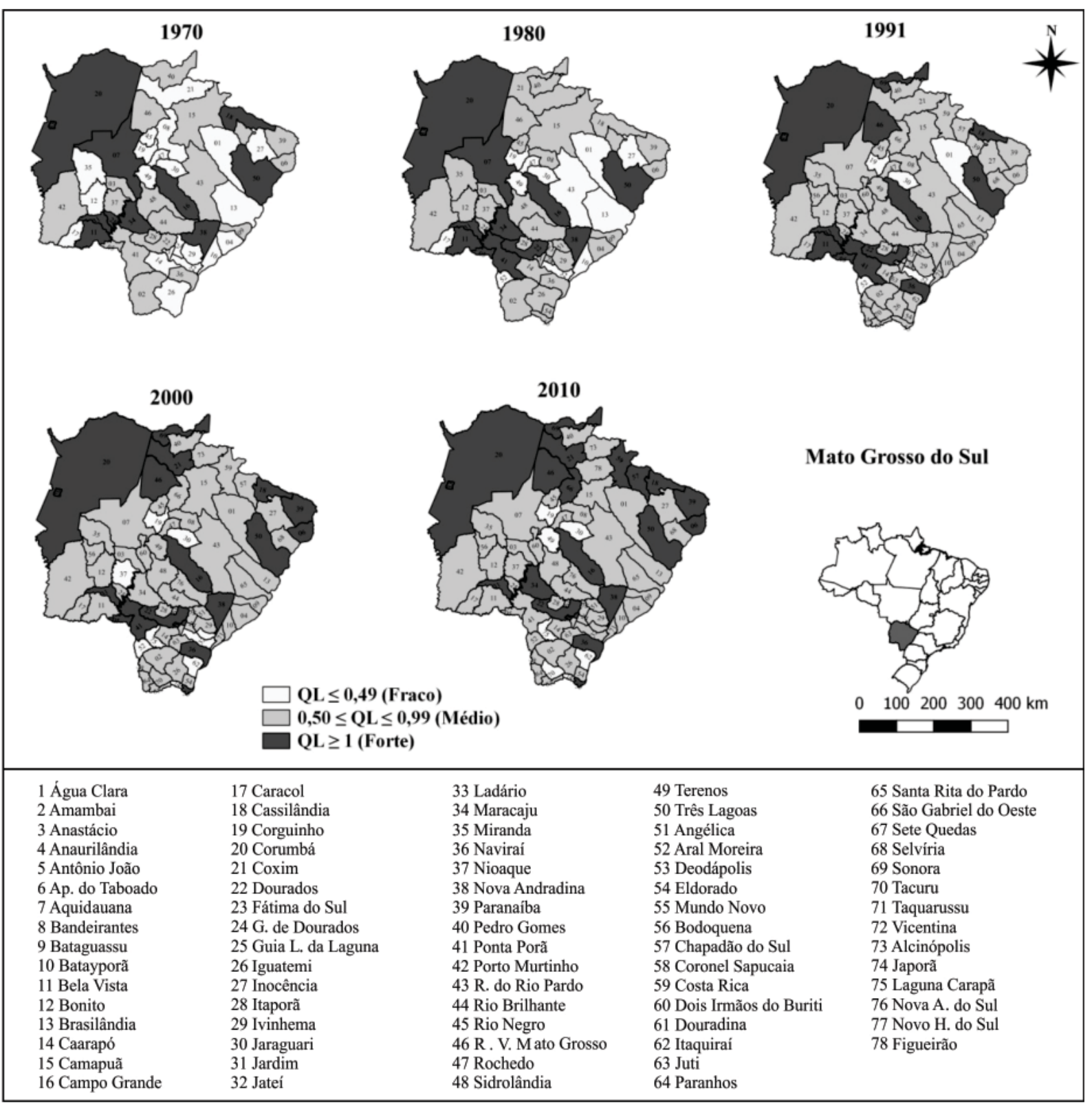

Figura 1 - Quociente Locacional da população urbana dos municípios de Mato Grosso do Sul 1970, 1980, 1991, 2000 e 2010

Fonte: Resultados da pesquisa a partir dos Censos Demográficos 1970, 1980, 1991, 2000 e 2010.

No entanto os municípios que concentraram maior parte da população urbana desde 1970 e/ou $1980^{7}$ são Campo Grande, Cassilândia, Corumbá, Dourados, Jardim, Ladário, Ponta Porã e

\footnotetext{
${ }^{7}$ Em 1980, vários municípios são instituídos, como os municípios polos Dourados e Ponta Porã.
} 
Três Lagoas. Desses municípios, apenas Cassilândia, Jardim e Ladário não são municípios polos de suas microrregiões (Figura 1).

O QL com valores abaixo de 0,49 , que considera municípios com baixa concentração populacional, demonstrou uma dispersão durante o período analisado, como pode ser observado na Figura 01. De 37,93\% dos municípios considerados com pouca concentração populacional em 1970, apenas 8,97\% ainda estão com baixa concentração. Esses aspectos refletem no âmbito da modernização agrícola que impulsionou a migração rural para o urbano.

A Figura 1 ainda apresenta que municípios com valor do QL considerado médio (0,50 até $0,99)$ foram os que apresentaram maiores crescimento no estado, estes representavam $25,86 \%$ em 1970, já em 2010 esta representatividade foi para 65,38\%. Percebe-se que desde a década de 1930 o estado se intensificou do rural para o urbano, sendo que os municípios que permaneceram com concentração populacional urbana baixa, são pequenos, recentemente instituídos e têm suas economias dependentes do agronegócio. Com base na Figura 1 e realizando um contraste com a Figura 2, evidencia-se, também, uma concentração da população rural do estado.

Na Figura 2, observa-se que o estado possui elevada concentração da população rural dos municípios, logo, apresenta-se uma dualidade, pois o perfil de concentração da população urbana apresentado na Figura 1 contrasta com o perfil de concentração rural apresentado pela Figura 2. Rippel (2013), ao estudar as transformações demográficas do oeste paranaense, constatou que as ocupações fundiárias da região são caracterizadas por pequenas propriedades, culminando em tal concentração da população rural.

No caso do estado de Mato Grosso do Sul, sua formação espacial pode ser explicada por Calixto e Gomes (2014), em que a ocupação fundiária ocorreu com grandes propriedades fundiárias e alguns centros urbanos. Os pequenos centros urbanos que formam maior parte do estado estão articulados a algum segmento (centro urbano), estes vinculados a atividades produtivas agrícolas, demandando serviços técnicos e especializados. A partir dessas características, pode-se dizer que o estado tem grande representatividade de atividade agrícola, impulsionado pelo agronegócio brasileiro, o que distingue a concentração da população rural. 


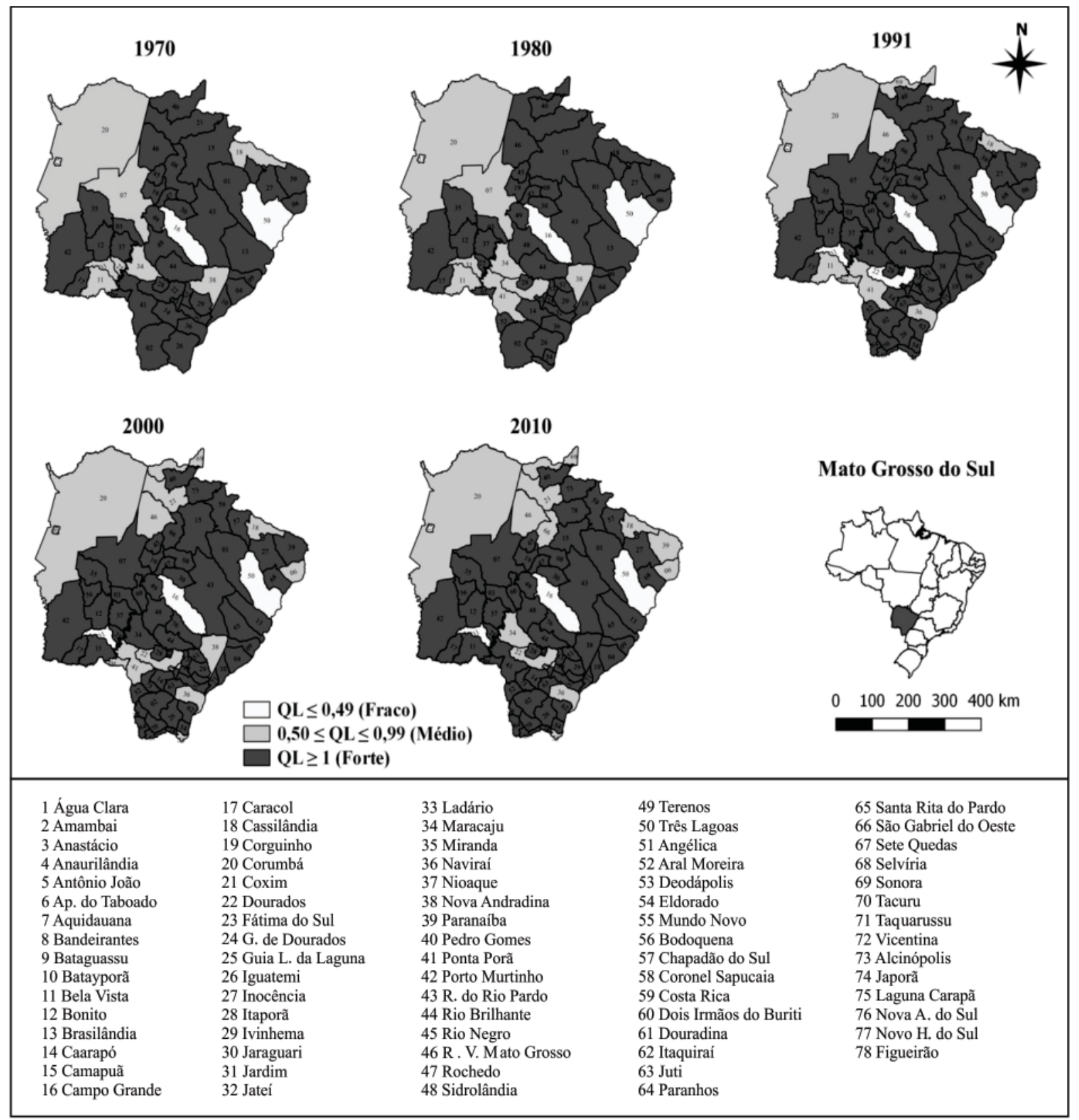

Figura 2 - Quociente Locacional da população rural dos municípios de Mato Grosso do Sul 1970, 1980, 1991, 2000 e 2010

Fonte: Resultados da pesquisa a partir dos Censos Demográficos 1970, 1980, 1991, 2000 e 2010.

Verifica-se, portanto, na Figura 2, que os grandes centros urbanos do estado, a capital Campo Grande e o município de Três Lagoas possuíram, ao longo das últimas cinco décadas, uma baixa concentração de população rural. Na questão dos municípios que concentraram população rural, em termos proporcionais, mantiveram-se em média $78,00 \%$ do estado. Para compreender tais aspectos, o Gráfico 1 indica a distribuição estadual da população urbana e rural para o período de 1970 a 2010, pelo Coeficiente de Localização (CL) em que valores próximos a um indicam concentração do domicílio rural ou urbano, e próximo a zero indicam maior distribuição do domicílio estudado. 


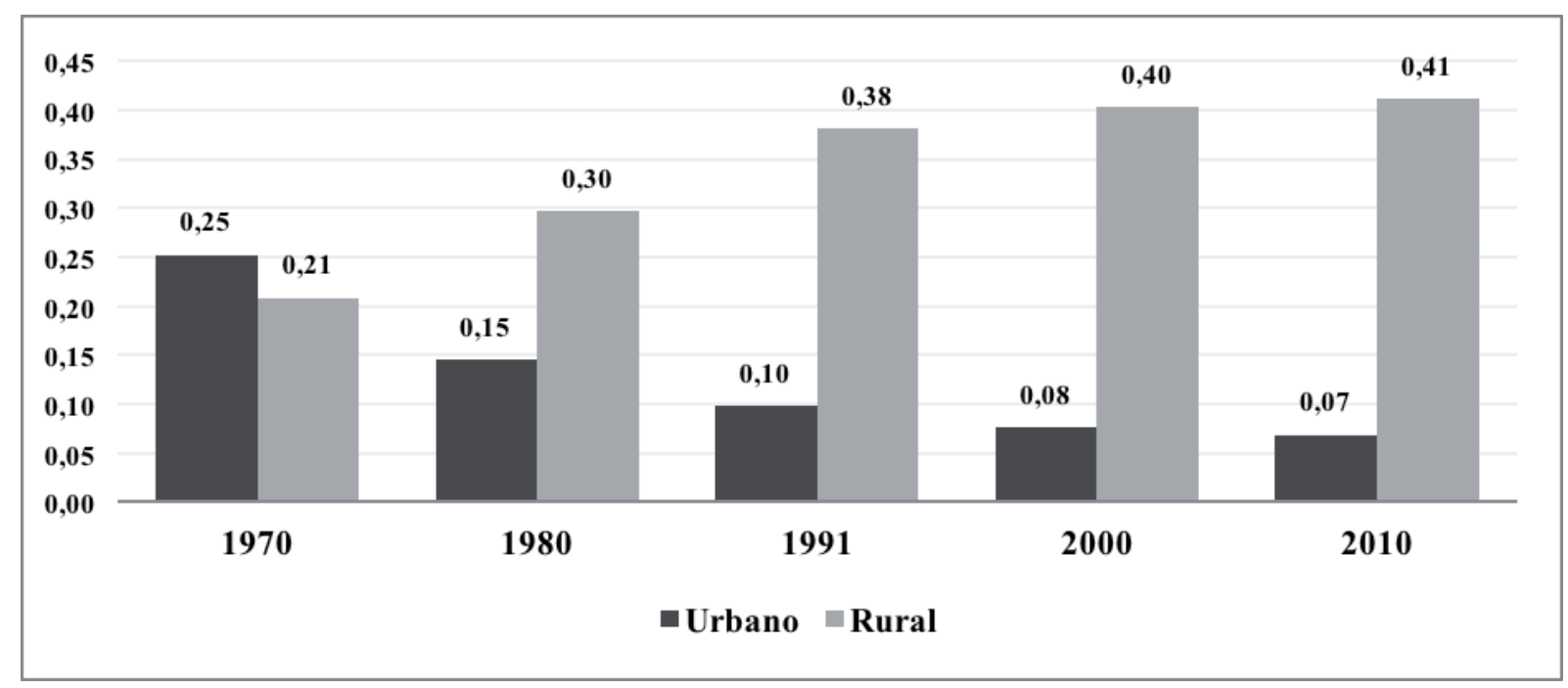

Gráfico 1 - Coeficiente de Localização (CL) - Mato Grosso do Sul - 1970-2010 Fonte: Resultados da pesquisa a partir dos Censos Demográficos 1970, 1980, 1991, 2000 e 2010.

Os dados apresentados no Gráfico 1 indicam que a distribuição da população rural se tornou mais concentrada e, ao mesmo modo, a população urbana disseminou-se pelo estado. De fato, a disseminação da população urbana ocorreu durante o período por centros urbanos do estado, com efeito, a partir da década de 1980, em que as políticas de planejamento econômico de ocupação da Região Centro-Oeste e a modernização agrícola já estão consolidadas.

Os coeficientes de localização da população urbana diminuíram desde a década de 1970, o que explica a ocorrência da urbanização nos municípios considerados polos do estado, como Campo Grande, Dourados, Ponta Porã e Três Lagoas. Essa disseminação da população urbana reflete uma tendência do movimento analisado quando se compara com o resultado dos Quocientes Locacionais urbanos analisados.

No Gráfico 2, indicam-se os dados do Coeficiente de Redistribuição (CRed), esse coeficiente é semelhante ao $\mathrm{CL}$, pois permite compreender os padrões de concentração ou dispersão espacial por dado domicílio. Entre o período de 1970 a 1991, os padrões de concentração da população urbana e rural eram mais evidentes, principalmente no caso da população rural; isto significa que houve importantes movimentos demográficos, que, a partir da década de 1990, os padrões demográficos tenderam a uma maior dispersão espacial. 


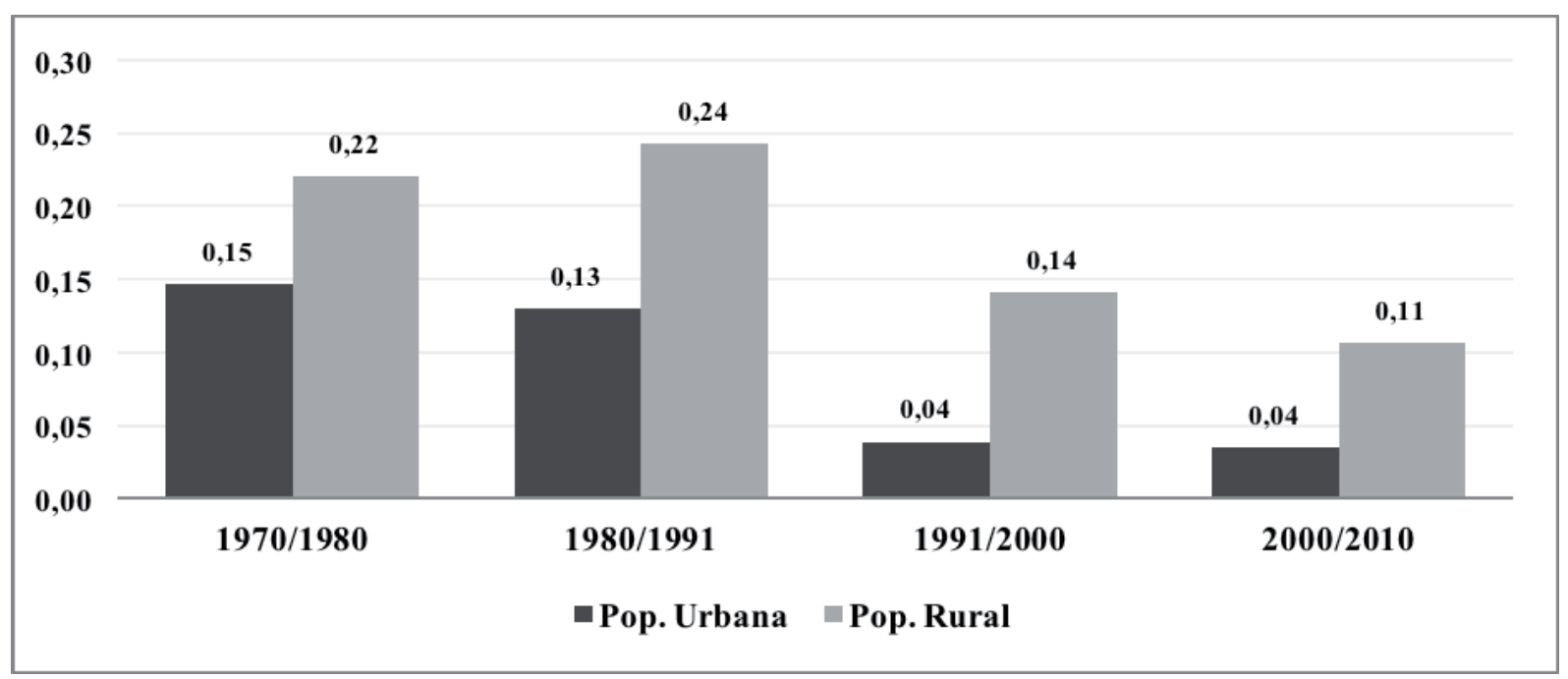

Gráfico 2 - Coeficiente de Redistribuição (CREd) - Mato Grosso do Sul - 1970 - 2010 Fonte: Resultados da pesquisa a partir dos Censos Demográficos 1970, 1980, 1991, 2000 e 2010.

De fato, os movimentos populacionais urbanos e rurais apontam para um estado que se torna mais urbano após a consolidação da fronteira agrícola (modernização) e dos planos governamentais aplicados para ocupação populacional. Contudo ainda é bastante distinta no estado a proporção da população rural, que, mesmo reduzindo ao longo dos anos, ainda aparece com um importante percentual da população total do território sul-mato-grossense, como se pode observar pelos dados apresentados na Tabela 1.

Tabela 1 - Distribuição da população urbana e rural - Mato Grosso do Sul - 1970-2010

\begin{tabular}{cccccc}
\hline Ano & Pop. Urbana & (\%) & Pop. Rural & (\%) & Pop. Total \\
\hline 1970 & 451.692 & 45,25 & 546.468 & 54,75 & 998.160 \\
1980 & 919.256 & 67,11 & 450.513 & 32,89 & 1.369 .769 \\
1991 & 1.414 .447 & 79,45 & 365.926 & 20,55 & 1.780 .373 \\
2000 & 1.747 .106 & 84,08 & 330.895 & 15,92 & 2.078 .001 \\
2010 & 2.097 .238 & 85,64 & 351.786 & 14,36 & 2.449 .024 \\
\hline
\end{tabular}

Fonte: IBGE (1970; 1980; 1991; 2000; 2010).

Pela Tabela 1, é possível verificar o crescimento contínuo da população urbana e o decrescimento contínuo da população rural já a partir da década de 1970. Pelo Censo de 2000 e 2010, as proporções mantiveram-se estáveis, consolidando em torno de 15\% correspondente à população rural. Esses aspectos confirmam que, apesar da grande concentração fundiária, a população rural do estado é consistente, mesmo após a expansão da fronteira agrícola, fatos esses que se apoiam nos pequenos municípios que têm como base as atividades agropecuárias.

Em 2010, por exemplo, segundo os dados do censo, 15 dos 79 municípios sul-mato-grossenses apresentaram população rural superior à urbana, todos com menos de 20.000 habitantes no total. Outro fator importante é que $70,88 \%$ dos municípios do estado possuem população inferior ao número de 20.000 habitantes, o que complementa a composição de cidades com pequenos núcleos urbanos e dependentes de atividades agropecuárias.

Apenas 4 municípios (Campo Grande, Corumbá, Dourados e Três Lagoas) concentraram população acima de 100.000 habitantes em 2010. Esses municípios também concentraram em 
torno de $49,14 \%$ da população que imigra para o estado, com destaque para capital Campo Grande, 30,57\% (IBGE, 2010).

Para compreender tal dinâmica, a circularidade migratória dos municípios torna-se uma importante abordagem, pois permite evidenciar as características migratórias do estado. Para tanto, Rippel (2015) utilizou o Índice de Eficácia Migratória (IEM), que serve para mensurar a eficácia do processo migratório de uma unidade territorial.

Nesse contexto, com base em Cunha (1997) e no Instituto Brasileiro de Geografia e Estatística (IBGE), os dados apresentados no Gráfico 3 indicam o Índice de Eficácia Migratória (IEM), cujo valor varia de 1 a-1, sendo que valores próximos a 1 indicam elevado processo migratório (ganhos populacionais) e valores próximos a-1 representam pouca dinâmica emigratória (perdas populacionais).

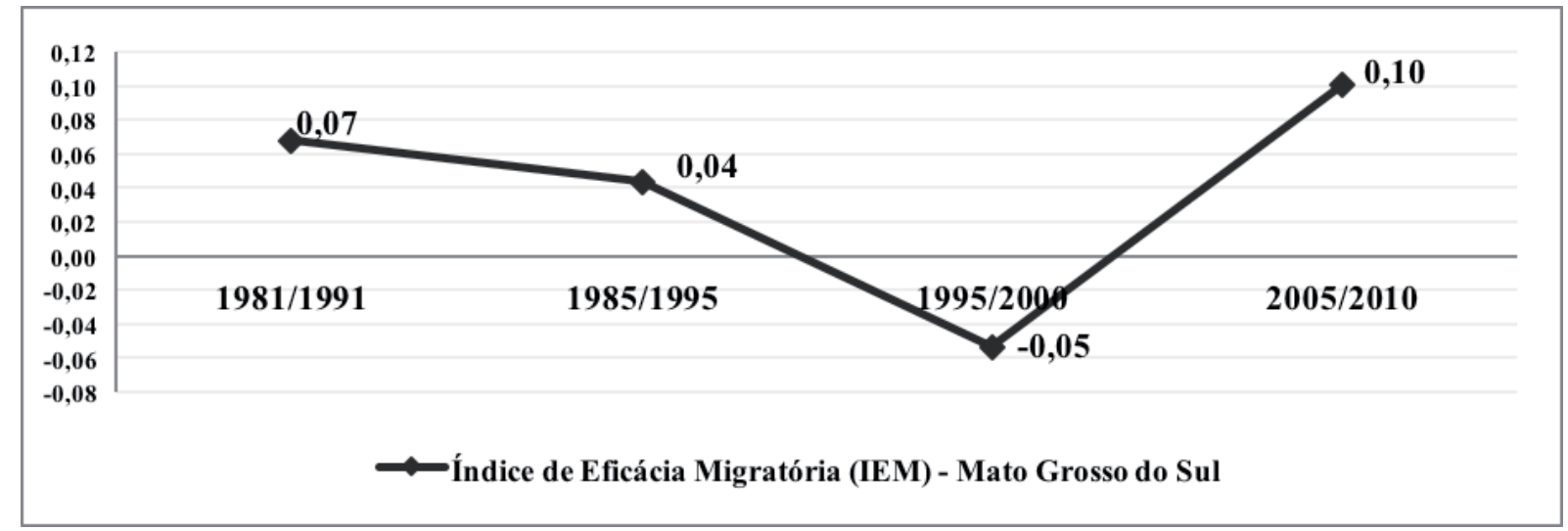

Gráfico 3 - Índice de Eficácia Migratória Interestadual* - Mato Grosso do Sul - 1980- 2010 *Para os anos de 1981 a 1995, os dados são encontrados em Cunha (1997).

Fonte: Cunha (1997) e IBGE (2010)

Os valores apresentados no Gráfico 3 do IEM demonstram valores próximos de zero, de que se deduz uma alta circularidade migratória entre as décadas de 1980 e 2000. Destaque para a segunda metade da década de 1990, em que o IEM, mesmo com valor próximo a zero, apresentou-se negativo, o que indica evasão populacional. Na segunda metade da década de 2000, a eficácia migratória apresentou seu maior valor, significando uma tendência imigratória no estado.

Cunha (1997) destaca que as imigrações das unidades federativas da Região Centro-Oeste estavam condicionadas pelo processo de consolidação da fronteira agrícola e pelo crescimento de grandes centros urbanos. Já a emigração, o autor constata que a extensão da fronteira agrícola para o Norte pode ser explicada para essa circularidade migratória (IEM próximo 0) nos estados de Mato Grosso, Mato Grosso do Sul, Goiás e Distrito Federal. Pela Tabela 2, é possível verificar a distribuição da população dos estados brasileiros para Mato Grosso do Sul, tendo como base o último censo demográfico de 2010. 
Tabela 2 - Distribuição da população migrante segundo estado de origem (2005-2010) - Mato Grosso do Sul - 2005/2010 - 1995/2000 e 1986/1991*

\begin{tabular}{lcccccc}
\hline \multirow{2}{*}{ UF de Origem } & \multicolumn{2}{c}{$\mathbf{2 0 0 5 / 2 0 1 0}$} & \multicolumn{2}{c}{$\mathbf{1 9 9 5 / 2 0 0 0}$} & \multicolumn{2}{c}{$\mathbf{1 9 8 6 / 1 9 9 1}$} \\
& No Pessoas & $\mathbf{\%}$ & No Pessoas & $\mathbf{\%}$ & No Pessoas & \% \\
\hline São Paulo & 33.457 & 33,80 & 36.250 & 37,10 & 41.888 & 33,77 \\
Paraná & 14.560 & 14,71 & 17.186 & 17,59 & 27.412 & 22,10 \\
Mato Grosso & 13.777 & 13,92 & 12.280 & 12,57 & 13.797 & 11,12 \\
Minas Gerais & 4.761 & 4,81 & 3.357 & 3,44 & 5.065 & 4,08 \\
Rio de Janeiro & 4.431 & 4,48 & 3.849 & 3,94 & 4.019 & 3,24 \\
Rio Grande do Sul & 3.843 & 3,88 & 4.258 & 4,36 & 7.158 & 5,77 \\
Goiás & 3.794 & 3,83 & 3.786 & 3,87 & 3.347 & 2,70 \\
Santa Catarina & 2.881 & 2,91 & 2.465 & 2,52 & 2.903 & 2,34 \\
Rondônia & 2.351 & 2,38 & 2.629 & 2,69 & 6.520 & 5,26 \\
Pernambuco & 2.319 & 2,34 & 1.862 & 1,91 & 2.028 & 1,63 \\
Outros estados & 12.798 & 12,93 & 9.787 & 10,02 & 9.912 & 7,99 \\
Total & 98.972 & 100,00 & 97.709 & 100,00 & 124.049 & 100,00 \\
\hline
\end{tabular}

*Os dados de censos anteriores não englobam Mato Grosso do Sul, devido a ser sua criação oficializada em 1979. Fonte: IBGE (1991; 2000; 2010).

Os estados que mais emigram população para Mato Grosso do Sul, são São Paulo, Paraná e Mato Grosso. Maior parte da população em 2010 origina-se das Regiões Sudeste (43,55\%), Sul (21,50\%) e do próprio Centro-Oeste (18,52\%), o que explica a saturação da fronteira agrícola nas regiões Sul e Sudeste a partir da década de 1980. Há uma boa parcela de estados do Nordeste, este representando 10,20\% em 2010. No processo histórico, Cunha (1997) destaca que boa parcela de nordestinos e de pessoas de outros estados do Centro-Oeste passou por São Paulo, o que ilustra uma proporção reduzida de paulistas segundo naturalidade no Centro-Oeste.

Outros aspectos importantes que Pochmann, Blanes e Amorim (2006) destacaram e que complementam com os dados da Tabela 2, são de que a urbanização sul-mato-grossense está associada à mudança do perfil da população migrante, pois, até os anos 2000, 79\% dos migrantes residiam em áreas urbanas, passando para $84 \%$ na década de 2000. Desse modo, as transformações demográficas do estado repercutiram tanto no âmbito intraestadual quanto interestadual. Além disso, os municípios de maior porte econômico e populacional tendem a concentrar mais população urbana, o inverso tende a ocorrer com municípios menores.

\section{CONSIDERAÇÕES FINAIS}

A investigação teve o objetivo analisar a evolução da concentração populacional urbana e rural do estado de Mato Grosso do Sul, entre os anos de 1970 e 2010. Pelos dados analisados, as transformações demográficas e o padrão de concentração urbana e rural entre os municípios sul-mato-grossenses ocorreram de forma mais intensa até a década de 1990, década em que a fronteira agrícola já se encontrava consolidada no estado.

Durante as últimas quatro décadas, o estado de Mato Grosso do Sul passou por importantes transformações socioeconômicas, que vão de uma estrutura produtiva de fornecedor de matéria-prima para o centro industrial brasileiro (São Paulo), para uma economia voltada ao mercado externo. Nesse processo, os movimentos populacionais e a distribuição espacial foram 
se consolidando, com diferentes intensidades, que definiram um estado mais urbanizado, mas que ainda tem importante representatividade da população rural.

Cabe ressaltar que o estado possui grande número de municípios que abrange menos de 20.000 habitantes, e que esses municípios concentram população rural, dado que sua base produtiva é a produção agropecuária, enquanto que os municípios com maiores estruturas de serviços e com maior concentração de população urbana, como Campo Grande, Corumbá, Dourados, Ponta Porã e Três Lagoas, fornecem serviços técnicos e especializados para os municípios de pequeno porte.

Verificou-se também que os fluxos migratórios dos municípios estão concentrados naqueles com população superior a 100.000 habitantes, com destaque para a capital do estado que corresponde a quase um terço da população que se instala no estado. Essas evidências condizem com os indicadores utilizados, em que todo o movimento demográfico se polarizou em determinados municípios do estado, e que, no conjunto migratório, percebeu-se que o estado apresentou uma interessante circularidade migratória desde 1980.

É importante destacar que existem outros aspectos que podem influenciar nos fluxos migratórios e que não foram observados especificamente neste trabalho, como por exemplo, análises a partir do debate do desenvolvimento e, principalmente, do desenvolvimento brasileiro, relacionado ao comportamento migratório às discussões teóricas no âmbito do desenvolvimento. Logo, a ampliação deste tipo de estudo se justifica na medida em que pode auxiliar na elucidação de aspectos que influenciam os movimentos migratórios na economia local, regional ou nacional.

\section{REFERÊNCIAS}

ABRAMOVAY, R. Paradigmas do capitalismo agrário em questão. São Paulo: HUCITEC, 1992.

ABREU, S. Planejamento governamental: a Sudeco no espaço mato-grossense: contexto, propósitos e contradições. 2001. Tese (Doutorado em Geografia) - FFLCH, Universidade de São Paulo (USP), São Paulo, 2001.

BAER, W. A Economia Brasileira. São Paulo: Nobel, 2003. 509p.

BAJRAJ, R. J.; VILLA, M.; RODRÍGUEZ, J. Población y desarollo em América Latina y el Caribe: un desafio para las políticas públicas. Santiago: Cepal, 2000. (Série población e desarollo). Disponível em: <https:// www.cepal.org/es/publicaciones/7218-poblacion-desarrollo-america-latina-caribe-un-desafio-politicaspublicas>. Acesso em: 13 jan. 2017.

BECKER, B.; EGLER, C. Brasil: uma nova potência regional na economia mundo. São Paulo: Bertrand Brasil, 1993.

BRASIL. Ministério da Integração Nacional. Plano Estratégico de Desenvolvimento do Centro-Oeste (20072020). Brasília, 2007. Disponível em: <http://www.sudeco.gov.br/documents/20182/25746/web_pdco_ full.pdf/947ff447-ad43-4e5f-a5e7-4cf28d8f5ad2>. Acesso em: 25 nov. 2015.

BRESSER-PEREIRA, L. C. Conceito histórico de desenvolvimento econômico. Rio de Janeiro: Revan, 2007.

CALIXTO, M. J. M. S.; GOMES, I. R. P. Da formação territorial à rede urbana do Mato Grosso do Sul. In: SEMINÁRIO INTERNACIONAL AMÉRICA PLATINA, 5., 2014. Anais... Dourados, MS, 2014. CD-Rom, p. 1-15.

CUNHA, J. M. P. da. Os movimentos migratórios no Centro-Oeste na década de 80. Cadernos de Demografia, Brasília, n. 4, p. 25-79, out. 1997.

FERRERA DE LIMA, J.; ALVES, L. R. Le continuum urbain et rural: le cas de la région Ouest du Paraná au Brésil. 79o Congrès de l'ACFAS. Colloque (624) de la section développement regional. Sherbrook: ACFAS, 2011.

INTERAÇÕES, Campo Grande, MS, v. 19, n. 2, p. 325-341, abr./jun. 2018 
FONSECA, Pedro César Dutra da. Desenvolvimentismo: a construção do conceito. Texto para discussão. Brasília/Rio de Janeiro: Ipea, 2015.

FURTADO, Celso. Desenvolvimento e subdesenvolvimento. 2. ed. Rio de Janeiro: Fundo de Cultura, 1963.

HADDAD, J. H. (Org.). Economia regional: teoria e métodos de análise. Fortaleza: BNB/ETIENE, 1989.

INSTITUTO BRASILEIRO DE GEOGRAFIA E ESTATÍSTICA (IBGE). Censo demográfico de 2010. Disponível em: <http://www.ibge.gov.br/home/estatistica/populacao/censo2010/>. Acesso em: 20 out. 2016.

Censo demográfico de 2000. Disponível em: <http://www.ibge.gov.br/home/estatistica/ populacao/censo2000/>. Acesso em: 20 out. 2016.

Contagem populacional de 1996. Disponível em: <http://www.ibge.gov.br/home/estatistica/ populacao/contagem/>. Acesso em: 30 set. 2016.

Censo demográfico de 1991. Disponível em: <http://www.ibge.gov.br/home/estatistica/ populacao/censodem/default_censo1991.shtm>. Acesso em: 28 set. 2016.

Censo demográfico de 1980. Disponível em: <http://www.ibge.gov.br/home/presidencia/noticias/ imprensa/ppts/0000000403.pdf>. Acesso em: 28 set. 2016.

Censo demográfico de 1970. Disponível em: <http://www.ibge.gov.br/home/presidencia/noticias/ imprensa/ppts/0000000403.pdf>. Acesso em: 28 set. 2016.

KON, A. A experiência brasileira de planejamento econômico governamental federal: análise dos planos implementados e suas consequências. In: Quatro décadas de planejamento econômico no Brasil. Revista de Administração de Empresas, São Paulo, v. 34, n. 3, p. 49-61 maio/jun. 1994. Disponível em: <http:// www.scielo.br/pdf/rae/v34n3/a05v34n3.pdf>. Acesso em: 10 nov. 2016.

LODDER , C. A. Padrões locacionais e desenvolvimento regional. Revista Brasileira de Economia, Rio de Janeiro, v. 28, n. 1, p. 3-128, jan./mar. 1974. Disponível em: <http:// bibliotecadigital.fgv.br/ojs/index.php/ rbe/article/view/126/6794>. Acesso em: 20 out. 2016.

MONDARDO, M. L. A dinâmica migratória do Paraná: o caso da região sudoeste ao longo do século XX. Revista brasileira de Estudos Populacionais, Rio de janeiro, v. 28, n. 1, p. 103-31, jan./jun. 2011.

OLIVEIRA, T. C. M. Agroindústria e reprodução do espaço. Campo Grande, MS: Ed. UFMS, 2003.

OLIVEIRA, A. U. A geografia agrária e as transformações territoriais recentes no campo brasileiro. In: CARLOS, A. F. A. (Org.). Novos caminhos da Geografia. São Paulo: Contexto, 1999.

POCHMANN, M.; BLANES, D.; AMORIM, R. Inclusão social: uma utopia possível - impacto das políticas públicas de Mato Grosso do Sul. São Paulo: Cortez, 2006.

RIPPEL, R. Migração numa fronteira em desenvolvimento - transformações demográficas no Sudoeste do Estado do Paraná. Revista de Ciências Empresariais da UNIPAR, Umuarama, PR, v. 16, n. 2, p. 169-87, jul./dez. 2015.

RIPPEL, R. Fronteiras em movimento- transformações demográficas numa região emblemática: o oeste paranaense de 1970 a 2010. In: ENCONTRO NACIONAL SOBRE MIGRAÇÕES, 8., 2013, Belo Horizonte. Anais... Belo Horizonte: UFMG/FACE/Cedeplar, 2013.

SINGER, P. Crescimento econômico e distribuição espacial da população. Revista de Economia Política, São Paulo, v. 2, n. 3, p. 31-52, jul./set. 1982.

SOUSA, J. U. P. Alguns desafios ao planejamento e desenvolvimento do Maranhão, Brasil: contexto histórico, obstáculos e estratégias de superação. Planejamento e políticas públicas, PPP, Brasília, n. 37, jul./dez. 2011. 


\section{Sobre os autores:}

Alexandre de Souza Corrêa: Doutorando em Desenvolvimento Regional e Agronegócio pela Universidade Estadual do Oeste do Paraná (UNIOESTE) e Professor do curso de Ciências Econômicas da Faculdade de Administração, Ciências Contábeis e Economia (FACE) da Universidade Federal da Grande Dourados (UFGD). E-mail: alexandrecorrea@ufgd.edu.br

Marcelino Armindo Monteiro: Mestre em Desenvolvimento Regional pela UTFPR. Doutorando em Desenvolvimento Regional e Agronegócio pela Universidade Estadual do Oeste do Paraná (UNIOESTE). E-mail: yuorna@gmail.com

Ricardo Rippel: Pós-Doutor em Demografia - Universidade Federal de Minas Gerais (UFMG), Doutor em Demografia - Universidade Estadual de Campinas (UNICAMP), Mestre em Desenvolvimento Econômico - Universidade Federal do Paraná (UFPR), Especialista em Teoria Econômica (UFPR), Professor Associado do Colegiado de Economia, do PGDRA - Programa de Mestrado e Doutorado em Desenvolvimento Regional e Agronegócio, e do PGE - Programa de Mestrado em Economia da Universidade Estadual do Oeste do Paraná (UNIOESTE), Campus de Toledo. Líder do Grupo de Estudos e Pesquisas em Agronegócio e Desenvolvimento Regional (GEPEC). E-mail: ricardoripel@yahoo.com

Eliane Aparecida Gracioli Rodrigues: Mestre em Desenvolvimento Regional pela Universidade de Santa Cruz do Sul. Doutoranda em Desenvolvimento Regional e Agronegócio pela Universidade Estadual do Oeste do Paraná (UNIOESTE).E-mail: eco1321@hotmail.com 
